\title{
DISCHARGE AND DURATION OF STAY EXPERIENCE IN NURSING HOMES
}

\author{
Kenton E. Winter, M.A.* \\ The Bureau of Public Health Economics, School of Public Health, The University of Michigan.
}

(Received 14 April 1964)

Most of the information currently available about nursing home patients has been obtained by sample or enumeration studies of the patients found in one or more homes as of a given date. Such studies have ascertained the demographic characteristics of the nursing home patient-population and have obtained information about the physicial condition of the patients, including ambulatory status, types and extent of infirmity and diagnosis, and their need for specific types of nursing and personal services. Because the studies have been cross-sectional in nature rather than longitudinal, they have not provided information about discharge and death in the nursing home patient-population nor about the duration of patient stay up to the point of discharge or death. Yet information about discharge and death rates and analysis of factors to which they are related can improve our capacity to estimate the need for nursing home beds. It can also shed light on the degree to which bed needs may be affected by changes in such parameters as (1) the eligibility requirements which determine the number of public assistance patients in nursing homes, and (2) the closeness of nursing home-hospital relationships which influences the number of patients admitted into nursing homes from general hospitals. This paper presents the data obtained about discharge, death and duration of stay that were obtained in a longitudinal study and the results of the analysis of some of the factors to which these are related.

\section{SOURCE OF THE DATA}

In the course of a pilot study of costs in proprietary, partnership and profitincorporated nursing homes, information was obtained about patient discharges and deaths during the 3-month period 1st July to 30th September 1962, in 69 such facilities. $\dagger$ These homes were located in two counties of Michigan (Wayne and Oakland) which contain and partially surround the Detroit metropolitan area. All 69 homes had been in operation under their current legal form of organization for at least 12 months prior to 1st July 1962. None had had any change in licensed bed capacity during this period, and none reported plans for such changes in the foreseeable future at the time the study was initiated. Stability in legal form of

\footnotetext{
*Lecturer and research associate.

$\lceil$ The pilot study of nursing home costs was supported in part by a research grant from the Social Security Administration, Department of Health, Education, and Welfare, Washington, D.C. The analysis of patient information beyond the point required by the purposes of the study of nursing home costs was supported in part by a supplementary research grant from the Social Security Administration.
} 
organization and unchanged licensed bed capacity were conditions imposed in the selection of nursing homes to be included in the study of costs. The 69 nursing homes in which information was obtained about patient discharges and deaths constituted 71 per cent of all licensed proprietary, partnership and profit-incorporated nursing homes in the two counties which initially met the two selection requirements stated above.

The information was gathered by means of a field survey in which all patients in the homes as of 30th June 1962 were first identified and enumerated. A daily record of admissions, discharges and deaths was introduced into each home as of 1st July, and discharges and deaths were recorded for both the 30th Junc patient-population (the Initial Census) and the patients newly admitted during the period 1st July to 30th September (the New Admissions Group). A questionnaire was completed for each patient in both the Initial Census and the New Admissions Group. Admission date, demographic characteristics, sources of financial support, source of admission (general hospital, other type of facility, private dwelling), certain aspects of patient condition, diagnosis and selected care needs were ascertained for each patient. These data were obtained from patient charts and interviews by project staff with the nursing supervisor in cach home. The present paper is concerned with (1) the 3-month live discharge and death rates in the Initial Census and the New Admissions Group, with their relation to certain demographic characteristics, sources of financial support and source of admission, and (2) the duration of patient stay in nursing homes and its relation to sources of support and source (type) of admission.*

The data comprise a complete record of the outflow of patients during a calendar period which is the same for all 69 homes. Thus the total population of discharges can be viewed as a single group, as can the population of patients from which it derived. Discharge and death rates, as well as duration of stay, can be studied in relation to factors thought or known to influence them within this single group. Because of the length of the period for which patient outflow was studied and the number of homes in which it was studied, the findings and relationships are likely to apply over a wider area and time span than the Detroit and surrounding area in the summer of $1962 . \dagger$ However, it is well known that substantial proportions of the patients found in nursing homes in the course of one-day sample and enumeration studies are reported to have been there for lengthy periods. Thus it is possible that the statistics of patient outflow over a given period of time will be dominated by the duration of stay and other characteristics of patients who die or are discharged alive from the group already in the home at the outset. The shorter the period for which patient outfiow is being measured, the greater is the likelihood of such domination. Patients already in the home at the outset consitute the surviving core of a series of

\footnotetext{
*It is planned in subsequent papers to examine discharge and death rates and duration of stay in relation to patient condition and care needs, and to study the group of 598 patients newly admitted into the 69 nursing homes during the 3-month period. The admission and discharge data will be studied at the level of the patient-population of each home, and analyzed in relation to the characteristics of the home itself.

†Unless it were that attributes peculiar to the community of nursing home location (such as its welfare medical care payment system, the closeness of working relationships among its physicians, hospitals and nursing homes, and the existence and scope of service offered by home care programs) are judged to be more important in determining discharge, death and duration of nursing home stay than attributes of individuals in the general population from which nursing home patients are drawn (such as age, family membership status, income and the prevalence of chronic diseases).
} 
groups admitted over a time interval spanned by the admission date of the surviving patient with the longest stay and that of the patients admitted on the day preceding the beginning of the period of measurement. Already eliminated from this surviving core are all the patients who were discharged alive or had died in the interval spanned by these two dates.* However, the subsequent period during which discharge and death are recorded is identical for each and every patient in the surviving core. On the other hand, every discharge and death occurring among patients admitted during the period of measurement is recorded; but the duration of the period for which they are recorded varies with admission date, being longest for patients admitted early in the period of measurement and shortest for those admitted at the end of the period. Accordingly, live discharges and deaths are in the tables and analyzed separately for the Initial Census and the New Admissions Group, as well as for the two groups combined.

\section{THREE-MONTH DISCHARGE AND DEATH EXPERIENCE IN THE NURSING HOME PATIENT-POPULATION}

As is indicated in Table 1, the disposition of patients over the 3-month period for which patient outflow was measured varied between the two patient groups. Only 10 per cent of the Initial Census of 2671 patients in the 69 homes were discharged alive during the subsequent 3 months. The corresponding percentage figure in the group of 598 patients newly admitted during the 3-month period was almost two and a half times as large (24 per cent). The death rate was twice as large in the New Admissions Group as in the Initial Census. Of the 3269 patients who were either in the home on 30th June 1962 or were admitted sometime during the next 3 months, 2701 (82 per cent) were still in the home at the end of the period. This group of 2701 patients would have constituted the Initial Census for the measurement of patient outflow during the period beginning 1st October. It can be seen from the table that 85 per cent of such an intital group would have been made up of patients already in the homes on 30th June.

TABLE 1. Three-MONTH PATIENT DisPostTION BY PATIENT GROUP

\begin{tabular}{lrrrrrr}
\hline \multirow{2}{*}{ Patient disposition } & \multicolumn{2}{c}{ Initial Census } & \multicolumn{2}{c}{ New } & Admissions & \multicolumn{2}{c}{ Both patient groups } \\
No. & \multicolumn{1}{c}{ No. } & $\%$ & No. & $\%$ & No. & $\%$ \\
\hline Live discharge & 266 & 10 & 145 & 24 & 411 & 13 \\
Deceased & 112 & 4 & 45 & 8 & 157 & 5 \\
Continued stay $\dagger$ & 2293 & 86 & 408 & 68 & 2701 & 82 \\
$\quad$ Total & 2671 & 100 & 598 & 100 & 3269 & 100 \\
\hline
\end{tabular}

$\lceil$ Tncludes a small number of patients who left the nursing home for short visits with relatives or short hospital stays during the period of measurement and returned to the home in accordance with their original plans.

The data in Table 2 afford a clear insight into the process whereby the duration of stay of an initial census of nursing home patients lengthens with the passage of time. Both live discharges and deaths occurred with the highest frequency among patients

*The length of this interval in the 'surviving core' examined here (i.e., the Initial Census) is not less than 5208 days, or 14.3 years! The domination of the statistics of patient outflow by discharges and deaths in the surviving core of patients is reflected strikingly in the fact that the shortest duration of stay in the 10 per cent of live and deceased discharges who had stayed in a nursing home the longest was 854 days, or 2.3 years. The longest duration of stay in this group was 3498 days, or 9.6 years. This group accounted for not less than 53 per cent of all days of nursing home care received by patients who died or were discharged alive during the 3 -month period. 
Table 2. Percentage of Inttial Census patients discharged and deceased, by duration of STAY TO 30 JUNE

(Percentages of all patients in each group)

\begin{tabular}{|c|c|c|c|}
\hline \multirow{3}{*}{ Duration of stay to 30 June } & \multicolumn{3}{|c|}{ Type of Discharge } \\
\hline & Live & Deceased & Both \\
\hline & 32 & 8 & 40 \\
\hline 1-2 mth & 24 & 9 & 33 \\
\hline $2-3 \mathrm{mth}$ & 15 & 8 & 23 \\
\hline $3-4 \mathrm{mth}$ & 17 & 3 & 20 \\
\hline $4-6 \mathrm{mth}$ & 11 & 3 & 14 \\
\hline $6-12 \mathrm{mth}$ & 8 & 3 & 11 \\
\hline $1-2 \mathrm{yr}$ & 5 & 4 & 9 \\
\hline $2-3 \mathrm{yr}$ & 5 & 4 & 9 \\
\hline $3-4 \mathrm{yr}$ & 5 & 2 & 7 \\
\hline $4-5 \mathrm{yr}$ & 3 & 2 & 5 \\
\hline $5 \mathrm{yr}+$ & 5 & 3 & 8 \\
\hline All & 10 & 4 & 14 \\
\hline Mean stay to 30 June (days) & 344 & 479 & 384 \\
\hline
\end{tabular}

in the Initial Census who had been in the home the shortest time prior to 1st July. No less than 32 per cent of the Initial Census patients with durations of stay up to 30th June of less than one month were discharged alive in the 3 months following; and 8 per cent of such patients died before the end of September. At the other extreme, only 3-5 per cent of patients in the Initial Census who had been in the home for 4 years or longer prior to 30th June were discharged alive, and only 2 per cent died in the 3 months beginning 1st July. On the basis of the data shown, one would conclude that the probability of live discharge from a nursing home (at least within a subsequent 3month period) in a given patient-population declines appreciably after a stay of 2 months, and the probability of fairly imminent death declines appreciably after 3 months.

In Table 3, live discharge rates (percentages of all patients discharged alive during the 3-month period), deceased discharge rates (percentages who difd) and combined discharge rates are presented separately for the Initial Census, the New Admissions Group and the two groups combined. The discharge rates are shown by a number of demographic characteristics to which the disposition (live discharge, death or continued stay) of nursing home patients is known or thought to be related. First, it is apparent that the live discharge rate exceeded the deceased in all demographic subgroups shown in the table with one exception and, in most subgroups, exceeded it by a wide margin. The sole exception was the group of patients in the Initial Census aged 90 or over. It should be recalled, however, that patients who left the nursing home alive but in a terminal stage are classified as live discharges, along with those who continued to live. Second, it is clear that the live discharge rate in the New Admissions Group exceeded that in the Initial Census for all demographic subgroups by ratios that varied from a low of 1.1 to 1 ( 10 and 9 per cent) among patients with living relatives other than spouse, children or siblings, to a high of 3.75 to 1 ( 30 and 8 per cent) in the case of patients aged 75-79 years. This was also true for the deceased discharge rate, with three exceptions. It was the same (5 per cent) among patients aged 80-84 in both patient groups and lower among patients with no living relatives in the New Admissions 
Table 3. Percentage of patients discharged and deceased, By Selected demographic CHARACTERISTICS

(Percentages of all patients in each group)

\begin{tabular}{|c|c|c|c|c|c|c|c|c|c|}
\hline \multirow{2}{*}{$\begin{array}{l}\text { Demographic } \\
\text { characteristic }\end{array}$} & \multicolumn{3}{|c|}{ Initial Census } & \multicolumn{3}{|c|}{ New Admissions } & \multicolumn{3}{|c|}{ Both patient groups } \\
\hline & Live & Deceased & Both & Live & Deceased & Both & Live & Deceased & Both \\
\hline \multicolumn{10}{|l|}{ Sex: } \\
\hline Male & 12 & 4 & 16 & 29 & 6 & 35 & 15 & 5 & 20 \\
\hline Female & 9 & 4 & 13 & 21 & 9 & 30 & 11 & 5 & 16 \\
\hline \multicolumn{10}{|l|}{ Race: } \\
\hline White & 10 & 5 & 15 & 24 & 8 & 32 & 13 & 5 & 18 \\
\hline Negro & 9 & 2 & 11 & 29 & 5 & 34 & 12 & 3 & 15 \\
\hline \multicolumn{10}{|l|}{ Age: } \\
\hline under 55 & 15 & - & 15 & 34 & - & 34 & 20 & - & 20 \\
\hline $55-64$ & 16 & 1 & 17 & 22 & 9 & 31 & 17 & 3 & 20 \\
\hline $65-69$ & 15 & 3 & 18 & 21 & 6 & 27 & 16 & 4 & 20 \\
\hline $70-74$ & 9 & 4 & 13 & 29 & 7 & 36 & 13 & 5 & 18 \\
\hline $75-79$ & 8 & 4 & 12 & 30 & 7 & 37 & 12 & 5 & 17 \\
\hline $80-84$ & 10 & 5 & 15 & 21 & 5 & 26 & 12 & 5 & 17 \\
\hline $85-89$ & 8 & 6 & 14 & 15 & 13 & 28 & 9 & 7 & 16 \\
\hline 90 or over & 5 & 6 & 11 & 18 & 11 & 29 & 7 & 7 & 14 \\
\hline \multicolumn{10}{|l|}{ Marital status: } \\
\hline Married & 13 & 5 & 18 & 30 & 10 & 40 & 18 & 7 & 25 \\
\hline Widowed & 9 & 5 & 14 & 23 & 8 & 31 & 11 & 5 & 16 \\
\hline Divorced, separated & 16 & 1 & 17 & 33 & 5 & 38 & 18 & 2 & 20 \\
\hline Single & 11 & 3 & 14 & 16 & 5 & 21 & 12 & 3 & 15 \\
\hline \multicolumn{10}{|l|}{ Family status: } \\
\hline Spouse with children & 14 & 5 & 19 & 25 & 8 & 33 & 16 & 6 & 22 \\
\hline Childless spouse & 11 & 5 & 16 & 35 & 12 & 47 & 21 & 8 & 29 \\
\hline $\begin{array}{l}\text { Widowed, divorced, } \\
\text { with children }\end{array}$ & 9 & 4 & 13 & 25 & 8 & 33 & 12 & 5 & 17 \\
\hline Closest relative a & & & & & & & & & \\
\hline sibling & 10 & 4 & 14 & 25 & 5 & 30 & 13 & 4 & 17 \\
\hline Other relatives only* & 9 & 4 & 13 & 10 & 5 & 15 & 9 & 4 & 13 \\
\hline No living relatives & 11 & 3 & 14 & 21 & 2 & 23 & 13 & 3 & 16 \\
\hline
\end{tabular}

*No relative closer than an aged parent, parent's sibling, cousin, nephew or neice.

Group ( 2 per cent) than in the Initial Census ( 3 per cent). In a third demographic subgroup (patients under 55 years of age) there were no deceased discharges within either patient group. In all the other such subgroups, the deceased discharge rate in the New Admissions Group exceeded that in the Initial Census by a factor that varied from a low of 1.25 to 1 ( 5 and 4 per cent) among patients who had neither spouse nor children but had other living relatives to a high of 9 to 1 ( 9 and 1 per cent) among patients between the ages of 55 and 64 .

Sex. The live discharge rate varicd with scx, bcing higher in both patient populations among males than among females. The deceased discharge rate was the same for patients of both sexes in the Initial Census, but in the New Admissions Group it was $1 \frac{1}{2}$ times as high for females ( 9 per cent) as for males (6 per cent).

Race. The live discharge rate was slightly higher (10 compared to 9 per cent) for whites than for negroes in the Initial Census, but somewhat lower ( 24 compared to 29 
per cent) in the New Admissions Group, while the deceased discharge rate of whites exceeded that of negroes in both patient groups.

Age. The live discharge rate varied with age in both patient groups, but rather more systematically in the Initial Census than in the New Admissions Group. In general, it decreased with increasing age. The deceased discharge rate varied more systematically than the live rate in both groups but within a narrower range, and increased with increasing age.

Marital status. The pattern of discharge rates varied with marital status, but not in any consistent way. The live rate was lowest $(9$ per cent) in the Initial Census for patients who were widowed and highest (16 per cent) for those who were divorced or separated. It was lowest (16 per cent) in the New Admissions Group for single patients and highest ( 33 per cent) for the divorced and separated. On the other hand, the deceased rate in the Initial Census was lowest (1 per cent) for the divorced or separated and highest ( 5 per cent) for the married and widowed. It was lowest ( 5 per cent) in the New Admissions Group among the divorced or separated and the single, and highest (10 per cent) among the married.

Family status. Discharge rates varied with family status (the existence of living relatives and the formal proximity of such relationships). As with marital status, which also enters into some of the distinctions made with respect to family status, the pattern of variation was not consistent over the two patient groups. In the Initial Census, the live discharge rate was lowest ( 9 per cent) for widowed, separated or divorced patients with children and those with relatives other than spouse, children or siblings, and highest (14 per cent) for those with spouse and children. In the New Admissions Group, it was lowest (10 per cent) again for those with relatives other than spouse, children or siblings and highest ( 35 per cent) for those with a childless spouse. The deceased rate varied slightly in the Initial Census, from a low of 3 per cent among those without living relatives to a high of 5 per cent among those with a childless spouse and those with both spouse and children. In the New Admissions Group, the variation was greater, with the low ( 2 per cent) again among those without living relatives and the high of 12 per cent among those who were childless but had a spouse.

The lack of explainable directions and magnitudes of difference in discharge rates in relation to most of the demographic factors included in the table is quite striking. Yet these include the factors which have been widely viewed as standing for the personal-situational characteristics that differentiale older people according to the nonmedical basis of need for continued stay in nursing homes. It has been argued, for example, that lack of close surviving relatives is responsible for an appreciable proportion of patients staying permanently in nursing homes when their needs for nursing and custodial care are minimal. If this were the case, one would expect to find the highest live discharge rate among patients with a full conjugal family of living relatives, i.e., a spouse with children available to lend their aging or aged parent (the patient's spouse) a hand in carrying out some of the responsbilities of caring for the patient at home after discharge. This would be expected particularly in the New Admissions Group, because of the recency of disruption of their home life. In the New Admissions Group, however, the live discharge rate is 40 per cent higher among patients whose closest living relative is a childless spouse than among those who also have children ( 35 compared to 25 per cent). And it is as high among those whose closest living relative is a sibling (generally as aged as the patient) as among those with 
spouse and children. In the Initial Census, the live discharge rate is, to be sure, highest among those with spouse and children. However, it is as high among those with no living relatives as among those with a childless spouse, the latter category of family status being the one with the highest live discharge rate in the New Admissions Group.

Nothing said above disputes the possibility that demographic factors, particularly those reflecting family membership status, may be very important in determining whether a patient with any given set of medical and nursing needs will be admitted into a nursing home or cared for elsewhere. It is evident, however, that demographic factors are either not associated with the probability of discharge in any systematic way, or that their influence on the discharge rate is obscured by a complex of interrelations among themselves. Such an interrelation might be, for example, a much younger age level among those without living relatives in the New Admissions Group than in the Initial Census group or between them and variables standing for aspects of patient condition that are really more important in determining discharge from nursing homes.*

Table 4. Percentage of Patients discharged and deceased, by sources of financial suPport AND AGE

(Percentages of all patients in each group)

\begin{tabular}{|c|c|c|c|c|c|c|c|c|c|}
\hline \multirow{2}{*}{$\begin{array}{c}\text { Sources of support } \\
\text { by Age }\end{array}$} & \multicolumn{3}{|c|}{ Initial Census } & \multicolumn{3}{|c|}{ New Admissions } & \multicolumn{3}{|c|}{ Both patient groups } \\
\hline & Live & Deceased & Both & Live & Deceased & Both & Live & Deceased & Both \\
\hline Under 70: & 15 & 2 & 17 & 24 & 6 & 30 & 17 & 3 & 20 \\
\hline $\begin{array}{l}\text { Private funds only } \dagger \\
\text { Private and public }\end{array}$ & 16 & 3 & 19 & 20 & 12 & 32 & 17 & 6 & 23 \\
\hline funds: & 6 & 2 & 8 & 15 & 4 & 19 & 7 & 2 & 9 \\
\hline Public funds only & 21 & 1 & 22 & 32 & 2 & 34 & 23 & 2 & 25 \\
\hline 70-79: & 8 & 4 & 12 & 29 & 7 & 36 & 13 & 5 & 18 \\
\hline $\begin{array}{l}\text { Private funds only } \dagger \\
\text { Private and public }\end{array}$ & 9 & 6 & 15 & 32 & 10 & 42 & 16 & 7 & 23 \\
\hline funds $\ddagger$ & 6 & 4 & 10 & 30 & - & 30 & 9 & 3 & 12 \\
\hline Public funds only & 9 & 3 & 12 & 21 & 3 & 24 & 11 & 3 & 14 \\
\hline 80 or over: & 9 & 5 & 14 & 19 & 9 & 28 & 10 & 6 & 16 \\
\hline $\begin{array}{l}\text { Private funds only } \dagger \\
\text { Private and public }\end{array}$ & 10 & 5 & 15 & 20 & 9 & 29 & 12 & 6 & 18 \\
\hline funds $\ddagger$ & 9 & 8 & 17 & 14 & 5 & 19 & 10 & 7 & 17 \\
\hline Public funds only & 7 & 4 & 11 & 19 & 9 & 28 & 9 & 4 & 13 \\
\hline All ages: & 10 & 4 & 14 & 24 & 8 & 32 & 13 & 5 & 18 \\
\hline $\begin{array}{l}\text { Private funds only } \dagger \\
\text { Private and public }\end{array}$ & 11 & 5 & 16 & 26 & 10 & 36 & 14 & 7 & 21 \\
\hline funds & 7 & 5 & 12 & 21 & 3 & 24 & 9 & 5 & 14 \\
\hline Public funds only & 11 & 3 & 14 & 23 & 5 & 28 & 13 & 3 & 16 \\
\hline
\end{tabular}

+Patient funds and contributions by responsible relatives. Includes a few cases in which the patient was being cared for free of charge by the home, due to being a relative of the operator or having exhausted his own resources.

$\Varangle$ Public funds include categorical assistance (primarily Old Age Assistance), county direct assistance funds and Medical Assistance to the Aged in a small number of cases.

*The investigation of discharge experience in relation to aspects of patient condition and care needs which is planned as the next stage in the analysis of the data obtained in this study should assist in deciding which of these two possibilities is the more likely. 
In Table 4, discharge rates are shown by the sources of the funds used to maintain the patient in the nursing home. Part of the variation attributable to the factor of age has been removed by showing rates for each type of financial support separately for three different age groups as well as for all ages combined. The age groupings were decided upon the basis of the relation of discharge rates to age shown in Table 3 . Without the intermediate control of age, variation in the discharge rates was relatively slight in both patient groups. In the New Admissions Group, the live discharge 1ate varied between a low of 21 per cent for patients supported by a combination of private and public funds and a high of 26 per cent for those supported wholly out of private funds. Deceased discharge rates varied between 3 per cent of the former group and 10 per cent of the latter. In the Initial Census, the live discharge rate was again lowest ( 7 per cent) for those supported by both private and public funds, and the same (11 per cent) for those supported wholly by either private or public funds. The deceased discharge rate was slightly lower for patients supported wholly out of public funds ( 3 per cent) than for those supported wholly from public or from private sources ( 5 per cent).

Variation in the live discharge rate in relation to sources of support was appreciably greater when the groups were classified by age. It varied differently with sources of financial support from one age group to another in both the Initial Census and the New Admissions Group.

In the New Admissions Group, it was highest (32 per cent) among patients under 70 years of age for those supported by public funds only. Among patients 70-79 and 80 or over, it was highest (again 32 per cent) for patients supported wholly by private funds, though in the latter age group the live discharge rate for those supported wholly out of private resources was only 1 per cent higher than for those supported wholly out of public funds ( 20 compared to 19 per cent). In the age group under 70 the live discharge rate for those supported wholly out of public funds ( 32 per cent) was appreciably higher than for those supported wholly out of private funds ( 20 per cent) or than for those supported by a combination of private and public funds. On the other hand, the deceased discharge rate was appreciably higher for those supported wholly out of private funds than in either of the other two support groups in both of the age groups under 80 . In the oldest of the three age groups, however, it was the same ( 9 per cent) for those supported wholly out of private as for those supported wholly out of public funds.

In the Initial Census, the live discharge rate also varied differently from one age group to another according to the sources of support. In the age group under 70, it was highest ( 21 per cent) for patients supported wholly out of public funds and lowest ( 6 per cent) for those supported by a combination of private and public funds. It was the same ( 9 per cent) for those wholly privately supported as for those wholly publicly supported in the age group 70-79, and highest ( 8 per cent) for those supported by a combination of private and public sources of funds in the age group 80 or over.

It thus cannot be said that the examination of discharge rates supports the contention that public assistance cases in nursing homes typically remain there in larger numbers than do those who are maintained out of private funds. It is apparent that the differences in discharge rate between those wholly and those partly supported out of public funds warrant further analysis. The two groups clearly differ with respect to 
factors related to duration of stay to a greater degree than is indicated merely by their relative degree of financial indigence.

In Table 5, discharge rates are shown by source of admission for all patients combined and for the same age groupings as in Table 4. In the New Admissions Group, the live and deceased discharge rates both varied substantially and in the same direction with source of admission. They were highest (32 per cent for live and 10 per cent for deceased discharges) for patients admitted from private dwellings and lowest (11 and 2 per cent) for those admitted from facilities other than general hospitals. In the Initial Census, variation in both discharge rates with source of admission was negligible. When age is introduced, it is seen that the range of variation in the live discharge rate with source of admission is considerably extended for those under 70 in the New Admissions Group. The introduction of age had little effect on the live discharge rate in the other two age groups in the New Admissions Group, or in any age group in the Initial Census. Nor did it affect the deceased discharge rate in either patient-population.

Table 5. Percentage of patients discharged and deceased, by source of admission and age (Percentages of all patients in each group)

\begin{tabular}{|c|c|c|c|c|c|c|c|c|c|}
\hline \multirow{2}{*}{$\begin{array}{c}\text { Source of admission } \\
\text { by Age }\end{array}$} & \multicolumn{3}{|c|}{ Initial Census } & \multicolumn{3}{|c|}{ New Admissions } & \multicolumn{3}{|c|}{ Both patient groups } \\
\hline & Live & Deceased & Both & Live & Deceased & Both & Live & Deceased & Both \\
\hline Under 70: & 15 & 2 & 17 & 24 & 6 & 30 & 17 & 3 & 20 \\
\hline Private dwelling & 17 & 2 & 19 & 34 & 一 & 34 & 20 & 2 & 22 \\
\hline General hospital & 14 & 2 & 16 & 28 & 11 & 39 & 17 & 4 & 21 \\
\hline Other facility* & 16 & 1 & 17 & 3 & - & 3 & 13 & 1 & 14 \\
\hline 70-79: & 8 & 4 & 12 & 29 & 7 & 36 & 13 & 5 & 18 \\
\hline Private dwelling & 7 & 4 & 11 & 38 & 11 & 49 & 14 & 6 & 20 \\
\hline General hospital & 10 & 4 & 14 & 25 & 6 & 31 & 13 & 5 & 18 \\
\hline Other facility* & 8 & 4 & 12 & 20 & 3 & 23 & 9 & 4 & 13 \\
\hline 80 or over: & 9 & 5 & 14 & 19 & 9 & 28 & 10 & 6 & 16 \\
\hline Private dwelling & 7 & 6 & 13 & 26 & 13 & 39 & 10 & 7 & 17 \\
\hline General hospital & 10 & 6 & 16 & 14 & 6 & 20 & 11 & 6 & 17 \\
\hline Other facility* & 10 & 4 & 14 & 11 & 3 & 14 & 10 & 4 & 14 \\
\hline All ages: & 10 & 4 & 14 & 24 & 8 & 32 & 13 & 5 & 18 \\
\hline Private dwelling & 9 & 5 & 13 & 32 & 10 & 42 & 13 & 6 & 19 \\
\hline General hospital & 11 & 4 & 15 & 23 & 8 & 31 & 13 & 5 & 18 \\
\hline Other facility* & 11 & 3 & 14 & 11 & 2 & 13 & 11 & 3 & 14 \\
\hline
\end{tabular}

*Primarily other nursing homes and county-operated medical care units but also, in a small number of cases, mental hospitals, boarding homes and a tuberculosis sanitorium.

In the New Admissions Group, variation in the live discharge rate with source of admission was systematic and quite pronounced in all three age classes, being highest for patients who had been admitted into nursing homes from their own homes or the homes of relatives and lowest for those admitted from facilities other than general hospitals. Variation in the live discharge rate with source of admission was most pronounced for those under 70 , ranging between a low of 3 per cent for those admitted 
from facilities other than general hospitals and a high of 34 per cent for those admitted from private dwellings. It was least pronounced but still appreciable for those aged 80 or over, being 11 per cent for those admitted from facilities other than general hospitals and 26 per cent for those admitted from private dwellings. There were no deceased discharges from the New Admissions Group during the 3-month period among patients under 70 years of age. In the two upper age groups, the pattern of variation with source of admission was systematic and in the same direction as the pattern for live discharges. The percentage of deceased discharges varied for patients aged 70-79 from a low of 3 per cent for those admitted from facilities other than general hospitals to a high of 11 per cent for those admitted from private dwellings. The corresponsling figures for patients aged 80 or over were 3 and 13 per cent.

Both the live and deceased discharge rates varied less widely with source of admission in the Initial Census, and the variation was not systematic from one age group to another. Thus the live discharge rate was highest (17 per cent) in the group under 70 for those admitted from private dwellings and lowest (14 per cent) for those admitted from general hospitals. For those aged 70-79, however, it was highest (10 per cent) for those admitted from general hospitals and lowest ( 7 per cent) for those admitted from private dwellings. In the oldest age gloup it was highest (10 per cent) for those admitted from general hospitals and other facilities and lowest (7 per cent) for those admitted from private homes. Variation with source of admission in the deceased discharge rate occurred only in two of the three age groups, and in both of these was very slight. Among patients under 70, it was 1 per cent for those admitted from facilities other than general hospitals and 2 per cent for those admitted from other sources. Among patients aged 80 or over, it was 4 per cent for those admitted from facilities other than general hospitals and 6 per cent for those admitted from other sources.

The pattern of differences in discharge rates between the New Admissions Group and the Initial Census may be interpreted in terms of a decrease in the effect of nursing home patient origin with increasing duration of stay, i.e., the longer the patient remains in the nursing home, the less the consequences of differences in source of admission. The pattern of discharge rates with respect to source of admission also has meaning in connection with the likely effects of increasing the closeness of working relationships between the nursing home and the general hospital. It has been argued that an increase in the proportion of nursing home patients admitted from general hospitals would result from closer working relationships between the two types of facilities and that this increase would tend to raise both live and deceased discharge rates in nursing homes. Discharge rates presumably would rise because a larger proportion of the total nursing home population would then be either post-hospital convalescent cases or post-hospital cases in terminal stages of illness. The data shown in Table 5 imply that this presumption would be valid only if two conditions relating to nursing home admission obiained; (1) that patients admitted from general hospitals were under 70 years of age, since this is the only age group in which either the live or the deceased discharge rate for patients admitted from general hospitals exceeded the rate for those admitted from private dwellings; (2) that the proportion of patients under age 70 at admission increase. In the New Admissions Group studied here, only 26 per cent of the patients were under 70 years of age, while 16 per cent were 80 or older. 


\section{DURATION OF STAY, DISCHARGE OR DEATH IN THE NURSING HOME PATIENT- POPULATION}

Up to this point, the discharge experience in the 69 participating homes over the 3-month period 1st July to 30th September 1962 has been presented and analyzed in terms of the percentages of all Initial Census patients and all New Admissions Group patients who were discharged alive or died during the period without regard to the duration of patient stay up to the time of discharge or death. In this section, data on duration of stay are presented and analyzed for the two patient groups separately and in combination. Since the data in the tables which follow are based only on the 378 live and deceased discharges from the Initial Census and the 190 from the New Admissions Group, it was not possible to show and analyze duration of stay separately for live and deceased discharges except for all patients in each of the two patient groups. The analysis of duration of patient stay is limited to the statistics of stay for live and deceased discharges separately in each patient group as a whole, and to an examination of stay in relation to the two factors of sources of financial support and source of admission. These two factors were selected on the basis of the pertinence of their relation to duration of stay to the current public issues of public welfare medical care financing and nursing home-hospital relationships.

TABLE 6. DURATION OF STAY, BY TYPE OF DISCHARGE AND PATIENT GROUP (Percentages of all discharges in each group)

\begin{tabular}{|c|c|c|c|c|c|c|c|c|c|}
\hline \multirow{2}{*}{ Duration of stay } & \multicolumn{3}{|c|}{ Initial Census } & \multicolumn{3}{|c|}{ New Admissions } & \multicolumn{3}{|c|}{ Both patient groups } \\
\hline & Live & Deceased & Both & Live & Deceased & Both & Live & Deceased & Both \\
\hline$<2 \mathrm{wk}$ & 1 & 一 & 1 & 47 & 44 & 46 & 18 & 13 & 16 \\
\hline $2 \mathrm{wk}-1 \mathrm{mth}$ & 4 & 4 & 4 & 23 & 27 & 24 & 11 & 10 & 11 \\
\hline $1-2 \mathrm{mth}$ & 15 & 10 & 13 & 26 & 27 & 26 & 19 & 14 & 17 \\
\hline 2-3 mth & 15 & 12 & 14 & 4 & 2 & 4 & 11 & 10 & 11 \\
\hline $3-6 \mathrm{mth}$ & 20 & 16 & 19 & - & 一 & - & 13 & 11 & 12 \\
\hline 6-12 mth & 15 & 11 & 14 & - & - & - & 9 & 8 & 9 \\
\hline $1-2$ yr & 13 & 25 & 16 & 一 & - & - & 8 & 18 & 11 \\
\hline $2 \mathrm{yr}+$ & 17 & 22 & 19 & - & - & - & 11 & 16 & 12 \\
\hline Total & 100 & 100 & 100 & 100 & 100 & 100 & 100 & 100 & 100 \\
\hline Mean stay (days) & 382 & 516 & 422 & 23 & 20 & 22 & 256 & 374 & 289 \\
\hline Median stay (days) & 146 & 328 & 175 & 16 & 16 & 16 & 70 & 104 & 78 \\
\hline
\end{tabular}

It can be seen from Table 6 that 23 per cent of all patients who were discharged alive or who died during the 3-month period beginning 1st July 1962 had stayed in the nursing home one year or longer and the mean duration of stay for all discharges was 289 days ( 9.5 months). These duration-of-stay figures are consistent with the impressions of lengthy stay derived from one-day enumeration and sample surveys of patients in nursing homes as of that date. The study of discharges and deaths makes it evident, however, that stays as long as the mean are far from typical. No less than 27 per cent of all patients were discharged or had died in less than one month after admission, and 50 per cent in 18 days or less. Duration of stay is longer for patients who die in nursing homes than for those discharged alive. Durations of stay of one year or longer were almost twice as frequent in the former group as in the latter, and both 
mean and median stay in the former group were almost $1 \frac{1}{2}$ times as long as in the latter.

The overall lengthier stay among patients who die in nursing homes is accounted for by those discharged and deceased from the Initial Census. No fewer than 47 per cent of those in the Initial Census who died during the 3-month period beginning 1st July had stayed one year or longer and the mean stay for the group was 516 days (17 months). Even in this group, however, the mean stay substantially exceeded the median stay of 328 days ( 10.8 months). The corresponding figures for those discharged alive show an appreciably shorter but still substantial duration of stay. Some 30 per cent had durations of stay of one year or longer and the mean stay was 382 days (12.6 months). However, 35 per cent of live discharges had stayed less than 3 months (91 days or less) and 50 per cent had stayed 146 days or less (4.8 months or less).

Duration of stay differed substantially from this pattern in the New Admissions Group, where no less than 46 per cent of those discharged and deceased had stayed less than two weeks, and the mean duration of stay was only 22 days. However, these figures must be interpreted in the light of the variation in admission date (and thus in possible duration of stay) over the 3-month period in the New Admissions Group. The longest stay possible for any newly-admitted patient who was discharged or died during the period was 91 days; $*$ and this duration could occur only in the case of patients who were admitted on 1st July and were not discharged or did not die until 30th September. In terms of the duration of stay groupings shown in Table 6, it is apparent that no member of the New Admissions Group who entered the home after 31 st July and was discharged or died during the 3-month period could have stayed '2-3-months'; no such patient who was admitted after 31 st August could have had a stay of as long as one month; and no such patient admitted after 16th September could have had a stay of as long as two weeks. In fact, patients who wcre discharged or died on the day of admission are the only ones for whom the probability of having their death or discharge counted in the 3-month period (if it occurred) was independent of admission date. $\dagger$ Thus the data presented in Table 6 for the New Admissions Group reflect stay over a calendar period that is the same for all such patients but the duration of stay involved for the individual patients varies with admission date, unlike the data presented for the Initial Census. However, variation in admission date does not limit the comparability of data on duration of stay as between the live and deceased members of the New Admissions Group. The substantial differences observed in the Initial Census are not evident in the New Admissions Group, where the percentages of

\footnotetext{
*Though the period contained 92 days on which patients could be admitted, the method recommended for counting hospital patient-days was used to count the number of days of care received by patients discharged and deceased. According to this method, the day of admission is included in the count and the day of discharge or death excluded. Thus for patients admitted on 1st July who were still in the home at midnight 30th September, the 3-month period included 92 patient-days. For 1st July admissions who were discharged or died on 30th September, the period included only 91 days. fIncluding those who were admitted and died or were discharged alive on 30th September, since the day of admission is counted as a day of stay, regardless of whether the patient survives or remains until the day following.

$¥$ The difference in duration of stay during the calendar period between the two patient groups is illustrated by the difference in mean duration of stay of the patients who continued their stay after 30th September. It was (of course) 92 days for such patients in the Initial Census. It was 46 days, or just half the maximum possible stay during the period, for such patients in the New Admissions Group.
} 
live and deceased discharges in all duration of stay categories are quite similar and where the mean stays differ only slightly and the median stays not at all.

TABLE 7. DURATION OF STAY, BY SOURCES OF FINANCIAL SUPPORT AND PATIENT GRoup

(Percentages of all live and deceased discharges in each group)

\begin{tabular}{|c|c|c|c|c|c|c|c|c|c|}
\hline \multirow{2}{*}{$\begin{array}{l}\text { Duration of } \\
\text { stay }\end{array}$} & \multicolumn{3}{|c|}{ Initial Census } & \multicolumn{3}{|c|}{ New Admissions } & \multicolumn{3}{|c|}{ Both patient groups } \\
\hline & $\begin{array}{l}\text { Private } \\
\text { sources }\end{array}$ & $\begin{array}{c}\text { Private } \\
\text { and } \\
\text { public }\end{array}$ & $\begin{array}{l}\text { Public } \\
\text { only }\end{array}$ & $\begin{array}{l}\text { Private } \\
\text { sources }\end{array}$ & $\begin{array}{l}\text { Private } \\
\text { and } \\
\text { public }\end{array}$ & $\begin{array}{l}\text { Public } \\
\text { only }\end{array}$ & $\begin{array}{l}\text { Private } \\
\text { sources }\end{array}$ & $\begin{array}{l}\text { Private } \\
\text { and } \\
\text { public }\end{array}$ & $\begin{array}{l}\text { Public } \\
\text { only }\end{array}$ \\
\hline$<2 \times k$ & 1 & - & 1 & 44 & * & 48 & 20 & 9 & 14 \\
\hline $2 \mathrm{wk}-1 \mathrm{mth}$ & 8 & 1 & 1 & 30 & * & 15 & 18 & 3 & 5 \\
\hline $1-2 \mathrm{mth}$ & 16 & 9 & 13 & 23 & * & 31 & 19 & 13 & 18 \\
\hline $2-3 \mathrm{mth}$ & 16 & 7 & 17 & 3 & * & 6 & 11 & 6 & 14 \\
\hline $3-6 \mathrm{mth}$ & 19 & 10 & 25 & - & - & - & 10 & 8 & 18 \\
\hline 6-12 mth & 19 & 11 & 9 & - & - & - & 10 & 9 & 7 \\
\hline $1-2 \mathrm{yr}$ & 11 & 25 & 17 & - & - & - & 6 & 21 & 12 \\
\hline $2 \mathrm{yr}+$ & 10 & 37 & 17 & - & - & - & 6 & 31 & 12 \\
\hline Total & 100 & 100 & 100 & 100 & $*$ & 100 & 100 & 100 & 100 \\
\hline Mean stay (days) & 301 & 686 & 381 & 22 & $*$ & 25 & 178 & 575 & 297 \\
\hline Median stay (days & s) 120 & 518 & 135 & 17 & * & 16 & 50 & 388 & 89 \\
\hline
\end{tabular}

*Too few cases to produce reliable figures.

In Table 7, duration of stay up to the date of discharge or death is shown in relation to the sources of financial support for the two patient groups separately and in combination. The small number of cases discharged from the New Admissions Group precludes presentation of live and deceased discharge rates separately, or even of the combined discharge rate for one subgroup of the New Admissions Group. Substantial variation in duration of stay occurs with respect to sources of support. Discharged and deceased patients whose nursing home care was being financed wholly out of their own resources and those of relatives typically had shorter durations of stay than did those supported partly or wholly out of public funds. And the difference in stay between those partly and those wholly maintained out of public funds is also pronounced. In both patient groups combined, no less than 38 per cent of patients supported wholly out of private funds had been discharged or had died in less than one month after admission, and one-half in 50 days or less. The corresponding figure was only half as large (19 per cent) for those financed wholly out of public finds, and less than one-third as large (12 per cent) for those financed by a combination of private and public funds. The mean duration of stay among those supported wholly by public funds was twothirdslonger than that for the private funds group, and among those supported by both private and public funds stay was well over three times as long as it was for those supported wholly out of private funds. The mean stay ( 575 days or 18.9 months) was typical for a much larger proportion of patients maintained out of a combination of public and private funds than for either of the other two groups.

The pattern observed in the combined group of discharged and deceased patients was found also in the Initial Census. In the New Admissions Group, differences in stay were slight. Duration of stay varied only slightly with sources of financial support, 
though the percentage of patients discharged or deceased after stays of one month or more was appreciably higher among those supported wholly by public funds than among those supported wholly out of private funds ( 37 compared to only 26 per cent).

Privately financed patients, it will be recalled (Table 4), had a combined discharge rate for the two patient groups taken together that was almost one-third higher than in the group supported wholly out of public funds and $1 \frac{1}{2}$ times as high as that in the group supported partly out of public funds. Substantially the same relative pattern of discharge rates obtained in the Initial Census and the New Admissions Group individually. Thus, in terms of both the factors that determine the total number of days of care received or rendered per patient admitted (discharge rate and duration of stay), it is clear that privately-financed nursing home patients rank lowest, publicly-financed patients next, and those financed by a combination of public and private funds highest. It remains to be seen whether this pattern can be accounted for by differences in those aspects of patient condition and care needs to which continuity of need for nursing home care is related.

TABLE 8. DURATION OF STAY, BY SOURCE OF ADMISSION AND PATIENT GROUP (Percentages of all live and deceased discharges in each group)

\begin{tabular}{|c|c|c|c|c|c|c|c|c|c|}
\hline \multirow{2}{*}{$\begin{array}{l}\text { Duration of } \\
\text { stay }\end{array}$} & \multicolumn{3}{|c|}{ Initial Census } & \multicolumn{3}{|c|}{ New Admissions } & \multicolumn{3}{|c|}{ Both patient groups } \\
\hline & $\begin{array}{l}\text { Private } \\
\text { dwelling }\end{array}$ & $\begin{array}{l}\text { General } \\
\text { hospital }\end{array}$ & $\begin{array}{l}\text { Other } \\
\text { facility }\end{array}$ & $\begin{array}{l}\text { Private } \\
\text { dwelling }\end{array}$ & $\begin{array}{l}\text { General } \\
\text { hospital }\end{array}$ & $\begin{array}{l}\text { Other } \\
\text { facility }\end{array}$ & $\begin{array}{l}\text { Private } \\
\text { dwelling }\end{array}$ & $\begin{array}{c}\text { General } \\
\mathrm{g} \text { hospital }\end{array}$ & $\begin{array}{l}\text { Other } \\
\text { facility }\end{array}$ \\
\hline$<2 \mathrm{wk}$ & 2 & 1 & 一 & 44 & 47 & * & 19 & 17 & 8 \\
\hline 2 wk-1 mth & 5 & 4 & 3 & 23 & 24 & * & 12 & 11 & 6 \\
\hline $1-2 \mathrm{mth}$ & 13 & 16 & 8 & 28 & 27 & * & 19 & 19 & 9 \\
\hline $2-3 \mathrm{mth}$ & 14 & 16 & 10 & 5 & 2 & * & 10 & 11 & 10 \\
\hline 3-6 mth & 16 & 21 & 16 & - & - & - & 10 & 14 & 13 \\
\hline $6-12 \mathrm{mth}$ & 13 & 13 & 16 & - & - & - & 8 & 9 & 13 \\
\hline $1-2 \mathrm{yr}$ & 12 & 14 & 29 & - & $\ldots$ & - & 7 & 9 & 25 \\
\hline $2 \mathrm{yr}+$ & 25 & 15 & 18 & - & 一 & - & 15 & 10 & 16 \\
\hline Total & 100 & 100 & 100 & 100 & 100 & * & 100 & 100 & 100 \\
\hline Mean stay (days) & 531 & 336 & 447 & 23 & 22 & $*$ & 323 & 230 & 385 \\
\hline Median stay (days & s) 183 & 123 & 333 & 17 & 16 & * & 59 & 71 & 222 \\
\hline
\end{tabular}

*Too few cases to produce reliable figures.

In Table 8, duration of stay is shown by source of admission for each patient group individually and for the two combined. In the combined group, the highest percentage of patients who had been discharged or had died within one month of admission (31 per cent) was found among those admitted from their own homes or the homes of relatives. The corresponding figure was 28 per cent for those admitted from general hospitals and only 14 per cent for those admitted from facilities other than general hospitals. On the other hand, stays of two years or more were $1 \frac{1}{2}$ times as frequent among those admitted from private homes ( 15 per cent) as among those admitted from hospitals (10 per cent) and almost as frequent as among those admitted from other facilities ( 16 per cent). This resulted in the lowest median stay ( 59 days or 1.9 months) being found for those admitted from private homes and the lowest mean stay (230 days or 7.6 months) being found for those admitted from hospitals. The longest duration of stay, whether expressed in terms of the percentage of discharged and 
deceased patients with long stays, or the mean or median stay, was experienced by patients admitted from facilities other than general hospitals.

The pattern of stay in relation to source of admission was somewhat different from this for patients in the Initial Census who were discharged or died. First, patients who had been admitted from general hospitals clearly had the shortest duration of stay in terms of the percentage staying less than 3 months, and in terms of the mean and median stay. Second; the longest mean stay (531 days or 17.5 months) was found in the group admitted from private homes rather than in the group admitted from facilities other than general hospitals (447 days or 14.7 months). This occurred even though the percentage of patients with stays shorter than 3 months was appreciably higher in the former than in the latter group ( 34 compared to 21 per cent). The pattern in general for the New Admissions Group was also in the direction of shorter stays for discharged and deceased patients who had been admitted from general hospitals. However, the differences between those admitted from private dwellings and from general hospitals were not large.

It will be recalled from Table 5 that the combined discharge rate was slightly higher for those admitted from general hospitals in the Initial Census and only slightly lower in the two groups combined than for those admitted from other sources. The mean duration of stay was substantially lower both in the Initial Census and in the combined patient group for patients who had been admitted from general hospitals than for those admitted from either of the other two sources. On balance then, the total number of days of care received or rendered per patient admitted is lowest for discharged and deceased nursing home patients who had been admitted from general hospitals.

\section{SUMMARY AND CONCLUSIONS}

Discharge, death and duration of stay have been examined over a 3-month period in 69 proprietary, partnership and profit-incorporated nursing homes. Though the study did not distinguish between those discharged alive but in a terminal stage and those discharged alive who went elsewhere to live, it is clear that live discharge from nursing homes occurs much more frequently than has commonly been supposed. The discharge rate was much higher in the groups with the shortest stay prior to the period for which patient outfiow was measured, and it was high enough on the average to support the conclusion that nursing homes in fact provide a substantial volume of short term care, in addition to the prolonged care for which they are already well-known. The demographic factors which have been thought of as reflecting personal-situational attributes that play a role in determining whether or not patients are admitted into and remain in or are discharged from nursing homes were found not to be related to discharge rates in any systematic fashion. Either these factors operate to influence discharge in a very complicated way, due to interrelationships among them, or the level of patient care needs is the factor of paramount importance in determining whether or not discharge takes place. Further study is needed to determine which of these possibilities actually obtains.

The analysis of duration of stay indicated that, though the mean stay was very lengthy, substantial proportions of live and deceased discharges had relatively short periods of stay. It was also seen that duration of stay varied in a highly systematic way with sources of financial support. Privately-supported nursing home patients, on the 
average, received the smallest number of patient-days of care. Whether this is due to differences in care needs that determine the feasibility of discharge and the duration of total stay remains to be ascertained. A somewhat less pronounced and systematic relationship between duration of stay and source of patient admission was established. In this instance, the combined discharge rate varied only slightly with source of admission in the Initial Census and the two patient groups combined. However, the mean stay of those admitted from general hospitals was low enough to make the total number of patient-days of care rendered to nursing home patients admitted from general hospitals the lowest with respect to source of admission. Here again, it remains to be seen whether substantial differences in patient condition and care needs are associated with differences in source of admission. 